\title{
DEAF CHILDREN LEARNING TO SIGN
}

\section{Jim Kyle}

\begin{abstract}
It used to be thought that deaf children had a language difficulty. Research we have carried out on deaf children in deaf families from the age of three months, indicates that deaf children learn sign language as effectively as hearing children learn to speak. In contrast, deaf children from hearing homes, even in signing programmes at school lag behind in the acquisition of sign language even up to the age of 11 years. Some initial intervention work has been carried out with families to introduce sign language earlier and several possible means of improving the language environment of deaf children are explored in this paper.
\end{abstract}

KEY-WORDS: Sign language ; Sign language acquisition ; Deaf children

RESUMO: Costumava-se pensar que as crianças surdas tinham dificuldade de linguagem. Uma pesquisa que realizamos com crianças surdas, de famílias surdas, a partir de 3 meses de idade, indica que crianças surdas aprendem a língua de sinais tão eficazmente quanto crianças ouvintes aprendem a falar. Em contraste, crianças surdas, de lares ouvintes, mesmo estando em programas para o aprendizado de sinais na escola, ficam atrás na aquisição da língua de sinais até a idade de 11 anos de idade. Alguns trabalhos iniciais de intervenção, que têm sido realizados com as famílias para introduzir a língua de sinais mais cedo, bem como vários meios possíveis de enriquecer o meio lingüístico de crianças surdas são explorados nesse artigo.

PALAVRAS-CHAVE: Língua de sinais ; Aquisição da língua de sinais ; Crianças surdas

\footnotetext{
${ }^{1}$ Trabalho apresentado na Segunda Conferência: Aquisição da linguagem de sinais e o desenvolvimento da criança surda, que integrou o Workshop A pessoa surda: aspectos de desenvolvimento/aprendizagem e contextos de educação bilingüe. Organização: Profas. Regina Maria de Souza (FE/GPPL/DEPE)e Marilda Cavalcanti (IEL/LA), Campinas: Faculdade de Medicina da UNICAMP, 22/03/2001.
} 
It seems obvious that deaf people should have access to a language as early as possible and they should achieve a mastery of this language at the same time as all children do. We can expect all children to arrive at school with a fully functioning language. Usually, this means that the child will share the same cultural experiences as the teacher and the general experiences of learning will be set within the everyday experiences of all members of that community. The educational curriculum comes from society's needs and expectations. When children come to school they should be ready to share and to contribute to those experiences.

But for 200 years there has been an expectation that deaf children cannot share those experiences because they are unable to hear and that they need specific additional tuition from designated professionals to give them the chance of taking part in society. This education of deaf children focuses on what is seen to be and the skills which they do not develop are the ones which they should be taught. That is, deaf children do not naturally speak well and so this is what education should be concerned with - instead of determining

the skills that deaf children have and the potential which can be reached through those. Deaf education became preoccupied with speech and the need to use hearing people to deliver that education. However, if it can be shown that def children can and do develop a natural language, then all of this changes. If research can chart the progress of sign language in young deaf children then the role of education is to use this language in the development of the child's cognition and learning.

Three aspects of this proposal are considered in this paper:

1. the early acquisition of sign language and the way in which it is achieved

2. the levels of achievement of signing in school

3. and the implications of the findings of the research for parents and teachers

\section{THE EARLY ACQUISITION OF SIGN LANGUAGE BY DEAF CHILDREN IN DEAF FAMILIES ${ }^{\text {[ }}$}

If we are to find the way in which sign language is acquired, then it seems clear that it should be in the situation of most effective language use - in a deaf family. What does the signing of a deaf mother look like and what are the stages of development which the child goes through?

Over the last 15 years ,m we have had the opportunity to study very young deaf children in deaf families in the community around Bristol in England. The overall numbers are small - 10 deaf children - but in a study of children from the age of three months to three years, filmed each moth at home and in the lab, this is a large study of the acquisition of sign language.

\footnotetext{
2 The data and analysis reported here is taken from joint work over a period of 15 years with Jennifer Ackerman, Bencie Woll and Lisa McEntee.
} 
Let us start with two examples:

Mother and Nancy are playing "pairs", choosing cards with animal pictures. Nancy's attention is suddenly caught by the "Happy birthday" chain hanging over the fireplace. She wants it removed because her birthday was last week.

Mother: Turkey!

Nancy: ?

All those ... where? (pointing to cards)

Not me (not my turn) wait, wait.

Take that; Take it off now (pointing at chain)

Take it off, I want it (off) now

Mother: Take what off?

Nancy: I want those (points to wall) now.

Mother: You want those taken off?

Nancy: Yes

Mother: Wait until we finish the game then I will take it off all right?

Nancy: I can't reach it. I can't. You reach it and take it off.

Mother: I'll ask Daddy to take it off. Wait for Daddy to come home and he'll take it off.

Nancy: Can't, can't. I can't reach it, I can't.

Mother: No, you can't reach it. Wait until Daddy comes home and takes it off.

Nancy: Leave it, leave it; leave it until later.

Nancy, aged 3 years, persists in trying to get the chain removed. There is nothing unusual about her insistence, nor her interaction, nor indeed in the content of her communication, except that the whole conversation was conducted in British Sign Language (BSL).

When Wells (1986) describes children's spoken language development, he presents many similar interactions.
Mark: Helen play, please? (He wants his sister to play)

Helen still in bed, Mummy?

Mother: (from next room) Mm?

Mark: Helen still - Helen still gone sleep,

Mummy?

Mother: No, she's up there talking, isn't she?

Mark: Yes, Helen come down? (request)

Mother: No, let her rest

Mark: All right, all right, Mummy.

There are many similarities in the two extracts. In both cases the child leads and pursues the topic following requests for clarification. In both cases, the child starts with an obscure reference to something which is not obvious to the mother. Both children show repetitions and both finally accept the mother's statements. Deaf children using BSL appear to function similarly in communication terms. Yet we know little about this language development.

Where does this development come from. For hearing children, the predominant model says that mother and child interact to create the meaning and that there are a range of features which develop in the child in order to achieve the meaning. The child is likely first to master intonation, and then single words and then gradually put words together and so on. We can also describe the progress in terms of function - requests, statements, questions.

In order to answer this question we were able to record a group of deaf children and have subjected the data from the video recordings to several sorts of analysis. 


\section{PRE-LANGUAGE - THE FIRST YEAR OF LIFE}

When we looked at the deaf mothers interacting with the children, we found differences from hearing interaction.

Deaf mothers use touch more, hearing mothers tend to use vocatives - often the baby's name. However, we also see the introduction of specific routines for attention getting and directing. Deaf mothers wait longer until they have eye contact and then name the object they wish to direct the child's attention to, and then point with hand and head (ie they look towards the object). In contrast, hearing mothers often point without warning and say "look over here!" Deaf mothers always name the object and this behaviour of naming characterises much of the first two years of life.

Deaf mothers seem to train attention. And it seems that this is almost the main activity of interaction in the first year of life. It sets the basis for future interaction for deaf children and is critically important. One aspect is especially significant - joint reference: the capacity to engage with an object or event separate from the immediate line of sight, is a key way in which hearing mothers can enrich the language development of the hearing child as she can indicate and then talk about an object while the child is engaged with it. For a deaf child this language enrichment has to be much more formal and precise - only when the child looks at the mother does the opportunity for interaction arise.
Through the first year, the mother tends to increase the complexity of utterances but there tends to be a drop in the length of utterance at around 6 months, when the child is beginning to focus on objects and the mother has to work harder to gain attention. This attention tends to be fleeting and so the opportunity for signing is reduced. Single sign utterances predominate in this period.

\section{INTERACTION AND MOTHERESE IN THE SECOND YEAR}

The continuation of attention games is apparent in the second year of life. Apart from tapping and waving, there was frequent use of pointing by the mother. This is different from simple attention-getting, as unlike tapping, pointing is integrated into sign utterances. Pointing most often took the form of touching with the index finger the object to which the child was attending; the mother reached round the child and pointed; the child turned round to face the mother and she continued with her utterance.

Mothers often adopted a tutorial role, teaching the child signs for objects. This was largely accomplished by the mother pointing to an object or a picture of an object, and either providing a model sign for the child or by signing "WHAT'S THAT". The mothers often provided a model of a sign for the child, and then acknowledged either the child's attempt to articulate the sign or some other indication by the child that he or she had understood the utterance, such as the child pointing at the appropriate picture. 


\section{CHILDREN SIGNING}

While we can see great differences between the deaf adult's form of interaction with the deaf child and the hearing parent's interaction with hearing children, the growth in sign of the deaf child does not look dissimilar to that of speech in the hearing child. Although there are gestures at the age of 10 or 11 months, the signing of individual verifiable signs is not until around 12 months - ie the same time as hearing children. These signs are poorly formed as are words in hearing children's speech and these can be seen in the video example.

\section{DEVELOPMENT OF SIGNING}

By transcribing the utterances of mother and child through all the filmed sessions between one year and three years, we were able to describe the child's development of sign language. The conclusions are taken from McEntee, Kyle \& Ackerman (1995):

\section{Increase in conversation with age:}

As one might expect, the extent and sophistication of deaf children's interaction in sign language increases as they become older. The greatest change is in the period between one year and two years, when (on the basis of spoken language research), we would expect the competence in conversation to be increasing most quickly. By the end of the second year, the child is able to initiate and terminate interactions - in effect, just in the same way that hearing children do. At this age, interaction proceeds mostly when the deaf mother seeks it out (i.e. initiates visually) and the interaction ends when the mother provides the requested information.

\section{Context for signing}

Although deaf children live in the same sort of housing and home environment as hearing children do, there seem to be major differences in the circumstances where language is used. While hearing families use mealtimes and bath-times as major opportunities for spoken language play and interaction, these seem less important to deaf families. The most common interaction situation was bookreading. Although this also occurs for hearing children, it is proportionately less frequent in random recordings in the home. The fact that book-reading is a highly regulated context, where divided attention may be easier to practise, is of some significance and deaf mothers seem to be comfortable with this task. In this situation, there is also the effect for the mother of being able to introduce vocabulary and simple grammatical constructions.

\section{Sign Production and Purpose}

The main interactions between deaf children and their parents involved the exchange of information. Supporting this is a high proportion of tutorial functions where parent or child attempts to provide a teaching context.

\section{Sentence Meanings}

In the same way we see the emergence of meaning in the children's utterances. These vary from simple comments on the locations of objects, to possession, and to a relatively small number of 
instances of time being specified. It may be that the richest semantic categories do not appear until later for these deaf children.

\section{ISSUES ARISING}

The simplest statement which we can make is that deaf children learning sign by the age of three years show that they are capable of learning all of the uses of language which hearing children achieve in speech. Although this may seem like a rather simple statement, it should be reiterated that until recently deaf children were viewed as deviant in language - this data confirms that this is not the case.

Deaf children may have problems in acquiring speech from hearing people, but deafness per se is not a barrier to language development.

\section{SIGN LANGUAGE IN SCHOOL}

Deaf children from hearing homes do not, during the period of early schooling, reach the competence of those who learned sign language in infancy. It is not a surprising finding, since it is one that linguists have been telling us was the case for a long time. All children ought to have their first experiences of language before they go to school. In some theories, there is a critical period when language should be learned. If deaf children have limited access to the language of their most effective communication - ie sign language during this early critical period, then they are likely to be affected in cognitive growth as well as language competence.
We carried out a study of deaf children between four and eleven years of age. This age range was chosen as it is a period when expected growth in sign language is great and where it could be studied in primary school classes. Seventy-seven children from schools for the deaf or units which have a policy of sign use, in four regions of England took part to ensure that the assessment measures took into account regional variations in signs and the influence of a variety of teaching methods. This offered a basis for determining sign development and provided the data necessary to proceed with evaluation of BSL levels of development.

Three quarters of the schools had teachers who used sign but in conjunction with speech. All locations had also deaf people who worked in the classroom at least part of the time.

\section{SOME RESULTS}

As the child becomes older, the number of signs used in general interaction with a deaf researcher increases but the length of utterance increases only slightly. In effect, older children do not reliably use more complex utterances.

In a measure of sign order comprehension (spatial grammar), the child was presented with two comparable pictures except that subject and object were reversed in them. The child was allowed to examine them briefly before the deaf assessor signed a particular sign ordering, indicating agent and object by the use of spatial location and by the ordering of the signs. 
In the production part of the measure which followed the comprehension task, children were shown a single picture with an agent and object and possibly indirect object (BOX(a) GIRL(b) CAKE GIVES) their task was to sign the picture in a way which reflected the arrangement of participants. They had to provide the grammatically correct spatially related utterance. Children were scored for correct elements in their production, subject, object and verb.

Children up to the age of six years are unlikely to understand the spatial grammar reliably, though there is a considerable variation. By the age of eight years the main features of the grammar in respect of location and directional verbs are understood in sign communication. However, even at 11 years there was still children unable to distinguish the meaning through the spatial grammar.

Perhaps the most obvious argument as to why this spatial grammar is not developing is the lack of a role model for it. If deaf children are using Englishinfluenced signing then spatial grammar will be impossible to use in those utterances. When we examine those children from deaf families we find that $35 \%$ of the completely correct items (subject, verb, object and location) come from those from deaf families even though they constitute only $9 \%$ of the sample. This can be linked to the finding in the comprehension part above, where all those from deaf families over the age of 7 years had maximum scores on the test and of the three aged 6 years and under, one was scoring above chance.
In a picture description task, we find that the youngest children produce mostly single signs which name elements of the picture and do not elaborate or comment on the picture at all.

When we examine vocabulary, we find that deaf children from deaf families perform much better than those form hearing homes but that in general terms, the results are rather poor. Deaf children even by 11 years of age, who are from hearing families, do not have a breadth of vocabulary in terms of reception or production which would be expected.

\section{IMPLICATIONS}

At first glance the results are relatively clear:

1. Deaf children learn language (sign language) at the correct time for their age when they are given the right environment

2. The way in which they learn sign language from their parents is different from the way in which hearing children learn from their hearing parents, but the same stages are reached

3. Deaf children entering programmes where signing is used at the age of 5 years or 6 years, do not immediately or quickly catch up in language

4. It remains the case that even if teachers are deaf or use sign language, they will not be able to teach the content of the curriculum to the children in the early years of schooling

What is not immediately clear is what to do to improve the situation and where to 
expend the effort to improve he situation. Certain possibilities exist:

1. introduce a pre-school intervention programme which provides a training programme for all parents (pre-school and school age)

2. Provide a sign language course for teachers and parents which focuses on child sign language

3. Ensure that the first year of elementary school is focused on sign language enrichment with continuous contact with deaf model signers

4. Introduce an assessment system for sign language to ensure that progress is being made - the assessments are for teachers, children and parents

5. Create a sign language curriculum for deaf children (just as there is a Portuguese curriculum)

It seems obvious that

- if children do not have a functional language in sign or in speech, then the teacher cannot do his or her job.

- if the teacher and student do not share a common language, neither the teacher nor the pupil can do their job.

Some of these points have been acted upon:

1. PRE-SCHOOL PROGRAMME DEAF CHILDREN AT HOME

\section{(BRISTOL) - TRAINING FOR PARENTS ${ }^{3}$}

As the majority of deaf children have hearing parents, there is a predictable mismatch in communication needs at home. In order to develop most effectively, deaf children need to be bilingual from as early an age as possible. In order to deal with this, in our situation, deaf parents were trained to work in the homes with the hearing families. A schedule of visits was drawn up and the deaf consultants visited each week to carry out a programme of activities which involved playing games with the deaf child and the family, instructing the family in sign and discussing communication with the family.

The purpose of this project in dealing with children from diagnosis to 11 years of age, was to:

(a) Provide a role model for the deaf child.

(b) Enable the family to become friendly with a deaf adult.

(c) Help hearing parents realise that deaf adults can be the same as themselves, and can master all the same personal and social skills - such as driving a car or buying a house.

(d) Help parents to be more positive and accepting of deafness in general.

(e) Introduce or improve signing skills in the home.

\footnotetext{
${ }^{3}$ This project was managed by Hilary Sutherland.
} 
In addition, there were family workshops arranged twice or three times a year(within the project and within the service), where the pattern of training linked to practice with the child was emphasised.

\section{THE PROCEDURE USED}

Having provided this initial training, the project was ready to respond to the needs of families identified by teachers in the pre-school service and then by teachers in the school for the deaf. The procedure used once a family was identified was:

(a) The teacher outlined the project to the family.

(b) The deaf coordinator met the family with the teacher.

(c) After having met the family and gained some insight into their circumstances, the deaf coordinator chose which deaf consultant would be most appropriate to work with the family.

(d) Finally, the coordinator introduced the deaf consultant to the family. The time and date was fixed for the deaf consultant to visit each week.

Most visits are in the evenings with the children at home, although some are held during the day. Each visit lasted for one hour and was usually on a weekly basis.

\section{THE STRUCTURE OF THE SESSIONS IN THE HOME}

A basic principle of the intervention is that the deaf consultant attempted to work with the whole family rather than become focused only on the deaf child.
The structure of each one-hour session was set out as follows:

(a) Game playing and family interaction (20 minutes) - playing games with toys, learning about taking turns, touching, social communication, how to explain.

(b) Sign language tuition (20 minutes) structured sign language programme, supported by written materials and videotapes.

(c) Informal discussion (20 minutes) - a chance for the parent to ask questions and voice their concerns.

The time periods gradually adapted to the needs of the family and so sign sessions might be longer if that was a need while the discussion session was initially much shorter as the deaf consultant and family took time to get to know each other.

After each visit we the deaf consultant prepared a progress sheet. This required responses to simple questions eg

Did this game work well?

Why not?

How did the signing session

work out? Or why didn't it work well?

This provides a record which allows us to determine see which aspects worked well and which did not. As a result of this analysis, some alterations were made in the second year. This involved the formation of blocks of 6 weeks when a specific topic was explored in greater detail eg story telling, attention, or vocabulary development.

One of the obvious effects of the programme was in the change of attitude 
of the parents. Most families reported a change in their perspective and some even began to attribute the problems which the deaf child faced, to other members of society. At the same time, the deaf consultant was able to forge a link with the child and allow the child to develop an awareness of his or her own deafness

\section{2. \& 4. SIGN LANGUAGE COURSES FOR TEACHERS AND PARENTS}

Again this ought to be an obvious point, that teachers need to have training in the language. Since it is a language then the training has to be approached in the same way that we would approach the learning of English - with lessons, materials, practice and assessment. In the UK there is a national training programme with a curriculum and assessment at three levels. Teachers take this and usually have to reach stage III to work effectively in a bilingual programme. Without a programme and targets for teachers there is little hope of bilingual developments. Teachers need to have clear models and ways to learn.

As a natural step beyond the language training, teachers and parents need access to a form of sign language which is appropriate for children. All hearing teachers in hearing schools have mastery of the child register of their own language - they know how to express delight, challenges, simplify and so on. Hearing teachers of sign language do not necessarily have a way to present information to children and do not necessarily understand children's sign language. It does not take more than a few minutes of watching deaf children's sign language on video to become convinced of this need. Interestingly, deaf workers in school may also need this course as they are unlikely to have deaf children themselves and will only have their own recollections of early childhood to fall back on and this will usually have been in an oral setting.

\section{CONCENTRATED LANGUAGE ACCESS}

Again, this is a clear implication of the lack of access which a deaf child has prior to arriving in school. The first year has to ensure that the child acquires enough of the sign language to be able to communicate with other children, with teachers and with deaf staff.

\section{SIGN LANGUAGE CURRICULUM}

Perhaps the most important challenge is to produce a curriculum for deaf children themselves, to learn about their language. Just as hearing children begin from the earliest age to think about their language through stories and songs, deaf children need to have structured access to their sign language in a way which will improve their capacity to use it and to analyse it.

\section{CONCLUSION}

Deaf children can be effective sign language learners and they should have the opportunity to achieve this in the preschool. However, there are negative consequences should they be unable to learn at the correct time. In order to deal with the problems a number of strategies have been proposed. 


\section{REFERENCES}

McENTEE， L. ; KYLE J.G. ; ACKERMAN, J. Deaf children developing sign : final report to Leverhulme. Trust, Bristol : Centre for Deaf Studies, 1995.

WELLS, 1986?????

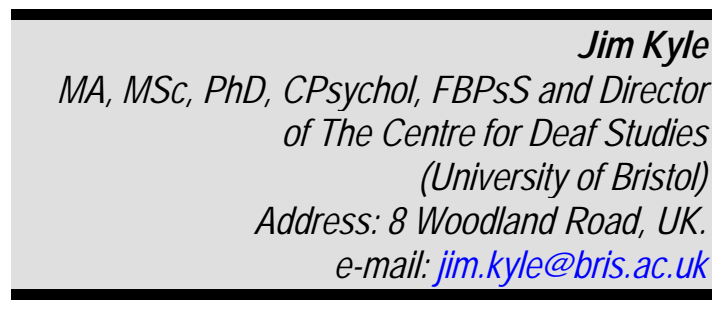

Rev. Online da Bibl. Prof. Joel Martins, Campinas, v.2, n.3, p.27-37, jun. 2001. 